\title{
Exploration of Sleep as a Specific Risk Factor for Poor Metabolic and Mental Health: A UK Biobank Study of 84,404 Participants
}

\author{
Gewei Zhu' \\ Sophie Cassidy ${ }^{2}$ \\ Hugo Hiden ${ }^{3}$ \\ Simon Woodman ${ }^{3}$ \\ Michael Trenell ${ }^{4}$ \\ David A Gunn ${ }^{5}$ \\ Michael Catt ${ }^{6}$ \\ Mark Birch-Machin 1,6 \\ Kirstie N Anderson ${ }^{7}$ \\ 'Faculty of Medical Sciences, Translational \\ and Clinical Research Institute, \\ Newcastle University, Newcastle Upon \\ Tyne, UK; ${ }^{2}$ Central Clinical School, \\ Faculty of Medicine and Health, The \\ University of Sydney, Sydney, NSW, \\ Australia; ${ }^{3}$ National Innovation Centre \\ for Data, School of Computing, The \\ Catalyst, Newcastle Helix, Newcastle \\ Upon Tyne, UK; ${ }^{4} \mathrm{NIHR}$ Innovation \\ Observatory, The Catalyst, Newcastle \\ Helix, Newcastle upon Tyne, UK; \\ ${ }^{5}$ Colworth Science Park, Sharnbrook, \\ Bedfordshire, UK; ${ }^{6}$ National Innovation \\ Centre for Ageing, The Catalyst, \\ Newcastle Helix, Newcastle upon Tyne, \\ UK; ${ }^{7}$ Department of Neurology, Royal \\ Victoria Infirmary, Newcastle upon \\ Tyne, UK
}

Purpose: Short and long sleep durations have adverse effects on physical and mental health. However, most studies are based on self-reported sleep duration and health status. Therefore, this longitudinal study aims to investigate objectively measured sleep duration and subsequent primary health care records in older adults to investigate the impact of sleep duration and fragmentation on physical and mental health.

Methods: Data on objective sleep duration were measured using accelerometry. Primary care health records were then obtained from the UK Biobank $(n=84,404)$. Participants (mean age, 62.4 years) were divided into five groups according to their sleep duration derived from the accelerometry data: $<5$ hours, 5-6 hours, 6-7 hours, 7-8 hours and $>8$ hours. ICD-10 codes were used for the analysis of primary care data. Wake after sleep onset, activity level during the least active 5 hours and episodes of movement during sleep were analysed as an indication for sleep fragmentation. Binary regression models were adjusted for age, gender and Townsend deprivation score.

Results: A "U-shaped" relationship was found between sleep duration and diseases including diabetes, hypertension and heart disease and depression. Short and long sleep durations and fragmented sleep were associated with increased odds of disease.

Conclusion: Six to eight hours of sleep, as well as less fragmented sleep, predicted better long-term metabolic and mental health.

Keywords: sleep, health, UK Biobank, primary care

\section{Plain Language Summary}

Most of the studies assessing the relationship between sleep and health utilised self-reported data. The current study used sleep data measured objectively by accelerometers and investigated the impact of poor sleep on subsequent health status extracted from primary care data in 84,404 UK Biobank participants 6 years later. This is by far the largest UK accelerometry study to assess poor sleep as a specific risk factor for future poor metabolic and mental health. A significant "U-shaped" association is established between sleep duration and subsequent physical and mental health, as those who sleep on average 6-8 hours/night have significantly less metabolic and mental health diseases later in life. Additionally, those with less fragmented sleep have significantly better metabolic and mental health.

\section{Introduction}

Sleep plays a vital role in many functions including memory consolidation, hormone secretion and the regulation of metabolic pathways. Sleep duration requirement varies 
with age. It is recommended that young and middle-aged adults should sleep on average 7-9 hours/night, but this reduces for older adults. ${ }^{1}$ Extensive research has shown a significant association between sleep and all-cause mortality risk. ${ }^{2}$ The Whitehall study demonstrated a clear "U-shaped" association between sleep duration and mortality. ${ }^{3}$ Previous studies have shown that very short sleep duration $(<5$ hours/ night) is related to higher mortality. ${ }^{4,5}$ Short sleep duration is also associated with impaired glucose tolerance and higher risk of diabetes, as well as increased coronary heart diseaserelated events. ${ }^{6,7}$ A longitudinal study demonstrated that those who get $\leq 5.5$ hours of sleep per night and those with a sleep duration reduced by $\geq 2$ hours/night have significantly higher risk of metabolic diseases 4 years later compared to those who usually get 7 hours of sleep per night. ${ }^{8}$ Apart from sleep duration, fragmented sleep has been associated with poorer cognitive performance. ${ }^{9}$ Evidence also suggests that people with longer sleep duration ( $>8$ hours/night) have an increased risk of all-cause mortality. ${ }^{5,10,11}$ Risk of coronary heart disease increases in people with a sleep duration of $>9$ hours/night. ${ }^{7}$ A longitudinal study carried out amongst the Chinese adult population found that a sleep duration $\geq 9$ hours/night is associated with increased odds of metabolic syndrome incidence 5 years later comparing to those who sleep $7-8$ hours/night. ${ }^{12}$ Additional to adverse physical health, longer sleep duration is associated with impaired cognition in older adults. ${ }^{9,13}$

Sleep physiology changes with age quantitatively and qualitatively. A decline in the ability to initiate and maintain sleep is part of the normal ageing process. ${ }^{14,15}$ Older adults commonly experience more fragmented sleep, shorter sleep duration and more daytime naps. ${ }^{14}$ However, some individuals are affected more than others, suggesting other factors may contribute to the interindividual variability. ${ }^{14}$ Existing research recognises the critical role played by gender. ${ }^{16,17}$ Psychosocial influences such as retirement, social isolation and bereavements may also contribute to the increased sleep complaints among older individuals. ${ }^{18}$ There is therefore interest in sleep duration as a potential biomarker for healthy or unhealthy ageing and a potentially modifiable risk factor.

Prior studies carried out using data from the UK Biobank found that poor sleep was associated with poorer health and depressive symptoms, however these were cross-sectional rather than longitudinal data. ${ }^{19}$ The combination of long sleep duration ( $\geq 9$ hours/night) and evening chronotype was linked to a higher cardiovascular risk. ${ }^{20}$ Short and long sleep durations were associated with impaired cognitive performances including slower reaction time and poorer visual memory. ${ }^{21,22}$ However, these studies used self-reported sleep duration rather than objectively measured sleep duration by actigraphy. ${ }^{23}$ Therefore, to overcome this limitation, the current study used sleeprelated actigraphy data.

The main objective of the current study was to investigate the relationship between sleep duration and fragmentation and subsequent health status over time using the UK Biobank data. This is by far the largest UK accelerometry study to assess objectively measured poor sleep as a specific risk factor for future poor metabolic and mental health.

\section{Methods}

\section{Population and Study Design}

Analysis was carried out using objectively assessed accelerometry and primary care data from the UK Biobank (Project ID: 43537). The UK Biobank received ethics approval from the North West Multi-centre Research Ethics Committee (Reference: 16/NW/0274). The UK Biobank also obtained generic Research Tissue Bank approval, which covers most research using the resource. Therefore, each applicant does not need to obtain separate ethics approval. The UK Biobank recruited approximately 500,000 participants between 2006 and 2010 from the general population of the UK who are aged 40-69 years old. Participants attended a baseline assessment to collect a wide range of measurements including height, weight and waist circumference. Biological samples including blood, saliva and urine were also collected. Self-completed touch-screen questionnaire and computer-assisted interviews collected information related to participants' sociodemographics and occupation, lifestyle, cognitive function, general health and medical history. Townsend deprivation index was also calculated using participants' postcode and national census immediately prior joining UK Biobank. Each participant is assigned a score based on where they live. ${ }^{24}$

\section{Accelerometry Data Collection}

Appropriate written consent was obtained from 103,712 participants studied between 2013 and 2015 (participants are now aged 43-79 years) to invite them to wear a wristworn accelerometer (Axivity AX3 triaxial accelerometer) continuously for 7 consecutive days on their dominant wrist. This allowed objectively measured physical activity and sleep/wake pattern data to be collected. ${ }^{24,25}$ 


\section{Primary Care Data Collection}

In collaboration with general practice (GP) systems suppliers, the UK Biobank subsequently extracted primary care data related to UK Biobank participants. These data included participants' health, all coded disease diagnoses, all current prescriptions, laboratory test results and immunisation records, as well as their interactions with their primary health care provider such as appointment dates. Data exchanged are in encrypted format and via secure transfer. These data were first released in 2019 on approximately 230,000 (45\%) UK Biobank participants. The hospital inpatient records cover diagnoses made since $1992 .{ }^{26}$ ICD-10 codes were used when analysing diagnosis related clinical information in the current study.

\section{Sleep Categories}

Accelerometry data were processed using $\mathrm{R}$ package GGIR version $1.7-1$. This has been previously validated and published as an open source. ${ }^{27}$ Various studies have assessed the general algorithm and its accuracy at detecting sleep period windows. ${ }^{28-30}$ The current study included participants with available processable accelerometry data and they are categorised into five groups according to their average sleep duration: 1) $<5$ hours/night, 2) 5-6 hours/ night, 3) 6-7 hours/night, 4) 7-8 hours/night, and 5) >8 hours/night.

\section{Optimal vs Less Optimal Sleep}

Sleep fragmentation-related measurements were also extracted from the accelerometry data that include wake after sleep onset (WASO), activity level of the least active 5 hours (L5 value) and number of episodes of movement (NBlock). Analysis was carried out to compare optimal and less optimal sleep where less optimal sleep is characterised as meeting all the following criteria: sleep duration $<5$ or $>8$ hours/night, WASO $\geq 95.98 \mathrm{~min}$ (75th percentile), L5 value $\geq 4.24$ milli-g (75th percentile) and NBlock $\geq 39.63$ (mid-point between its bimodal distribution).

\section{Statistical Analysis}

Statistical analysis was carried out using IBM SPSS Statistics version 26 (Armonk, New York, USA). The relationship between sleep groups and disease-related variables was examined using Chi-square test. Significance levels were set at the $5 \%$ level. Once a significant difference was detected between any sleep groups, column proportions of each variable were then compared using $z$-test and the Bonferroni method was used to adjust p-values. Therefore, if two columns were assigned the same letter in the result tables, it meant that they were not significantly different from each other ( $p>0.05)$, but if two columns had different letters, then the difference between them is statistically significant $(p<0.05)$. The exact significant level was estimated using the Monte Carlo method with $99 \%$ confidence level.

Participants were categorized into four age groups (4349 years, 50-59 years, 60-69 years and 70-79 years) and Townsend deprivation index were divided into quintiles (from 0 to 4, where 0 represents the least deprived individuals). Binary logistic regression models were used to calculate the odds ratio of various disease characteristics and they were adjusted for age (reference $=$ ' $43-49^{\prime}$ ); gender (reference $=$ "Female") and Townsend deprivation index (reference $=$ 'Least deprived). P-values $<0.05$ were accepted as statistically significant. Adjusted odds ratios (OR), with 95\% confidence interval (CI) are reported.

\section{Results}

After excluding those with unprocessable data, 84,404 participants $(47,528(56.3 \%)$ females and 36,876 (43.7\%) males) were included in the current study (Figure 1). The mean age of those participants was $62.35( \pm 7.84)$ years. Of these participants, 14,632 (17.3\%) slept $<5$ hours/night, 21,889 (25.9\%) slept 5-6 hours/night, 28,233 (33.4\%) slept 6-7 hours/night, 15,757 (18.7\%) slept 7-8 hours/night and 3893 (4.6\%) slept $>8$ hours/night. When combined sleep duration and sleep fragmentation-related measurements, 58,282 (69.1\%)

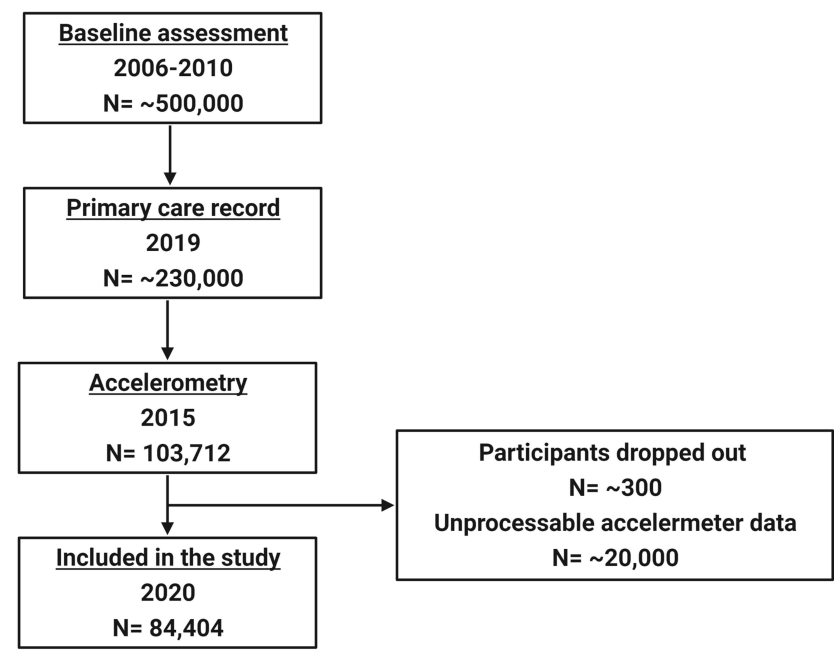

Figure I Flow chart showing the timeline of data released by the UK Biobank and the number of participants at each stage. However, only those with valid processable accelerometry data are included in the current study $(n=84,404)$. 
participants are classified as having optimal sleep and the remaining 26,122 (30.9\%) participants have less optimal sleep.

\section{Disease Prevalence Within the UK Biobank Population}

Prevalence of diseases expressed as percentages is presented in Table 1. It is apparent that the prevalence rate is relatively low for many diseases. The least prevalent disease group is "Schizophrenia/schizotypal/delusional diseases", which has a prevalence rate of $0.11 \%$, while the most prevalence disease is "Hypertensive diseases", which has a prevalence rate of $17.63 \%$.

Table 2 summarises the number of participants with certain diseases in each sleep group. A "U-Shaped" curve was observed in most diseases as illustrated in Figure 2. Those who sleep $<5$ hours/night are significantly more likely to have diabetes, disorders of glucose regulation, obesity, mental disorder, and various heart diseases. On the other hand, those who sleep $>8$ hours/night are more likely to have schizophrenia, mood disorders, pulmonary heart disease and cerebrovascular heart disease. Closer inspection of the table shows no significant difference was detected between "6-7 hours" and "7-8 hours" sleep groups in all diseases.

Table I Prevalence of Various Diseases Within the UK Biobank Population

\begin{tabular}{|l|c|}
\hline Disease & Prevalence (\%) \\
\hline Diabetes & 3.94 \\
\hline $\begin{array}{l}\text { Disorders of glucose regulation and pancreatic } \\
\text { internal secretion }\end{array}$ & 0.14 \\
\hline Obesity and other hyperalimentation & 2.74 \\
\hline Organic mental disorder & 0.20 \\
\hline Schizophrenia/schizotypal/delusional disorders & 0.11 \\
\hline Mood disorder & 2.58 \\
\hline Hypertensive diseases & 17.63 \\
\hline Ischaemic heart diseases & 6.28 \\
\hline Pulmonary heart diseases & 0.90 \\
\hline Other form of heart disease & 4.94 \\
\hline Cerebrovascular disease & 1.43 \\
\hline Diseases of arteries, arterioles and capillaries & 1.46 \\
\hline
\end{tabular}

Notes: Prevalence of diseases are calculated by dividing the number of cases by the total number of participants included in the current study $(n=84,404)$.

\section{Binary Regression Model}

Compared with those who sleep 7-8 hours/night, participants who sleep $<5$ hours/night have a higher risk of disease over the subsequent 5-7 years. It can be seen from the data in Table 4 that they are $58 \%, 48 \%, 106 \%$ and $44 \%$ more like to have diabetes, obesity and other hyperalimentation, organic mental disorder and mood disorders, respectively. When assessing cardiovascular health, those who sleep $<5$ hours/night are $36 \%, 25 \%, 33 \%, 27 \%, 37 \%$ and $36 \%$ more likely to have hypertensive diseases, ischaemic heart diseases, pulmonary heart diseases, cerebrovascular heart diseases, other forms of heart diseases, and diseases of arteries, arterioles and capillaries, respectively.

On the other hand, those with longer sleep durations (>8 hours/night) are $116 \%, 461 \%$ and $55 \%$ more likely to have organic mental disorder, schizophrenia/schizotypal/ delusional disorders and mood disorders, respectively, when compared to those who sleep 7-8 hours/night. They are also $11 \%, 17 \%, 72 \%, 22 \%, 58 \%$ and $32 \%$ more likely to have hypertensive disease, ischaemic heart diseases, pulmonary heart diseases, cerebrovascular heart diseases, other forms of heart diseases, and diseases of arteries, arterioles and capillaries, respectively, compared with those in the "7-8 hours" sleep group (Table 3).

Those with less optimal sleep are $42 \%, 73 \%$ and $40 \%$ more likely to have diabetes, glucose dysregulation and obesity, as well as $77 \%, 110 \%$ and $68 \%$ more likely to have organic mental disorder, schizophrenia/schizotypal/ delusional disorders and mood disorders, respectively, when compared to those with optimal sleep. They are also $22 \%, 12 \%, 37 \%$ and $13 \%$ more likely to have hypertensive disease, ischaemic heart diseases, pulmonary heart diseases, and other forms of heart diseases, respectively, compared with those with optimal sleep (Table 4).

\section{Discussion}

Using the largest accelerometry cohort to date, this study demonstrated a "U-shaped" relationship between objectively measured sleep duration and subsequent disease status indicating that short and long sleep durations, as well as fragmented sleep are associated with worse physical and mental health in the subsequent 5-7 years. This is in agreement with Li et al's findings, which found that compared to 7 hours of sleep, $<6$ or $>8$ hours of sleep per night is linked with higher risk of metabolic syndrome and hyperglycaemia 4 years later. ${ }^{31}$ Among the middle-aged and older adult population, sleep $<6$ hours at night-time is also associated with 
Table 2 Percentage of Participants with Various Diseases in Each Sleep Group

\begin{tabular}{|c|c|c|c|c|c|}
\hline & $\begin{array}{l}<5 \text { Hours } \\
(n=\mid 4,632)\end{array}$ & $\begin{array}{l}5-6 \text { Hours } \\
(n=21,889)\end{array}$ & $\begin{array}{l}\text { 6-7 Hours } \\
(n=28,233)\end{array}$ & $\begin{array}{l}7-8 \text { Hours } \\
(n=15,757)\end{array}$ & $\begin{array}{l}>8 \text { Hours } \\
(n=3893)\end{array}$ \\
\hline Diabetes (\%) & $6.6 \mathrm{a}$ & $3.7 \mathrm{~b}$ & $3.3 \mathrm{~b}, \mathrm{c}$ & $3.1 \mathrm{c}$ & $3.2 \mathrm{~b}, \mathrm{c}$ \\
\hline $\begin{array}{l}\text { Disorders of glucose regulation and pancreatic } \\
\text { internal secretion (\%) }\end{array}$ & $0.2 \mathrm{a}$ & $0.1 \mathrm{a}, \mathrm{b}$ & $0.1 \mathrm{~b}$ & $0.1 \mathrm{a}, \mathrm{b}$ & $0.2 \mathrm{a}, \mathrm{b}$ \\
\hline Obesity and other hyperalimentation (\%) & $4.5 \mathrm{a}$ & $2.8 \mathrm{~b}$ & $2.3 \mathrm{c}$ & $2.1 \mathrm{c}$ & $2.0 \mathrm{c}$ \\
\hline Organic mental disorder (\%) & $0.3 \mathrm{a}$ & $0.1 \mathrm{~b}$ & $0.2 \mathrm{~b}$ & $0.2 \mathrm{~b}$ & $0.3 \mathrm{a}, \mathrm{b}$ \\
\hline Schizophrenia/schizotypal/delusional disorders (\%) & $0.1 \mathrm{a}$ & $0.1 \mathrm{a}$ & $0.1 \mathrm{a}$ & $0.1 \mathrm{a}$ & $0.5 \mathrm{~b}$ \\
\hline Mood disorder (\%) & $3.6 \mathrm{a}$ & $2.3 \mathrm{~b}$ & $2.1 \mathrm{~b}$ & $2.5 \mathrm{~b}$ & $3.9 \mathrm{a}$ \\
\hline Hypertensive diseases (\%) & $23.5 \mathrm{a}$ & $17.2 \mathrm{~b}$ & $16.0 \mathrm{c}$ & $15.7 \mathrm{c}$ & 17.2 b,c \\
\hline Ischaemic heart diseases (\%) & $8.4 \mathrm{a}$ & $6.5 \mathrm{~b}$ & $5.5 \mathrm{c}$ & $5.4 \mathrm{c}$ & $6.3 \mathrm{~b}, \mathrm{c}$ \\
\hline Pulmonary heart diseases (\%) & $1.2 \mathrm{a}$ & $0.9 \mathrm{~b}$ & $0.8 \mathrm{~b}$ & $0.8 \mathrm{~b}$ & $1.4 \mathrm{a}$ \\
\hline Other form of heart disease (\%) & $6.6 \mathrm{a}$ & $4.9 \mathrm{~b}$ & $4.6 \mathrm{~b}, \mathrm{c}$ & $4.1 \mathrm{c}$ & $5.0 \mathrm{~b}, \mathrm{c}$ \\
\hline Cerebrovascular disease (\%) & $1.8 \mathrm{a}$ & $1.5 \mathrm{a}, \mathrm{b}$ & $1.3 \mathrm{~b}$ & $1.2 \mathrm{~b}$ & $1.9 \mathrm{a}$ \\
\hline Diseases of arteries, arterioles and capillaries (\%) & $1.9 \mathrm{a}$ & $1.5 \mathrm{a}, \mathrm{b}$ & $1.3 \mathrm{~b}, \mathrm{c}$ & $1.2 \mathrm{c}$ & I.6 a,b,c \\
\hline
\end{tabular}

Notes: Column proportion was compared using a z-test. If two columns are assigned the same letter, then the different between them are not statistically significant $(p>0.05)$. However, if two columns are assigned different letters, then the difference between them are statistically significant $(p<0.05)$.

depressive symptoms, but the symptoms can be improved with longer daytime naps. ${ }^{32}$ Previous UK Biobank sleep studies commonly used self-reported sleep duration. A crosssectional study design involving 477,529 UK Biobank participants found that cognitive performance is impaired in those with short ( $<7$ hours/night) and long ( $>9$ hours/night) selfreported sleep durations. ${ }^{22}$ Another study evaluated the importance of sleep duration on cardiometabolic health in 233,110 UK Biobank participants and results indicated that those with cardiometabolic disease profile including diabetes and cardiovascular diseases are more likely to report poor sleep $\left(<7\right.$ or $>8$ hours/night).$^{33}$ Several accelerometry studies have assessed sleep objectively, but the sample sizes are smaller. ${ }^{4,9,34,35}$ Additionally, many prior UK Biobank studies utilised self-reported disease status and self-completed mental health questionnaires data rather than data extracted from primary care health records. ${ }^{22,36}$ In reviewing the literature, no one has to date assessed both the primary care and accelerometry data in the UK Biobank cohort in a longitudinal fashion.

The overall "U-shaped" relationship between sleep duration and disease status is consistent with previous studies, which showed higher prevalence of poor health among those who sleep $<6$ hours/night, ${ }^{37}$ and sleeping for approximately 7 hours/night is linked with lower risk of cardiovascular disease, coronary heart disease and stroke. ${ }^{38}$ On closer inspection, even though the percentage of participants diagnosed with diseases including disorders of glucose regulation, organic mental disorder and hypertensive diseases is higher in long sleepers ( $>8$ hours/night) compared to those who sleep between 5 and 8 hours/night, the difference between them was not statistically significant. It remains controversial whether long sleep duration has direct adverse effects on health as many studies attempted to identify the underlying mechanism of long sleep that causes morbidity and mortality. It is thought that depressive symptoms and low socioeconomic status might be potential confounders, so it is possible that the two peaks of a "U-shaped" association do not mean the same thing. ${ }^{39}$

In the current study, extreme short sleep duration $(<5$ hours/night) increased the risk of diabetes by $58 \%$ and obesity by $48 \%$, in comparison to 7-8 hours of sleep. This is in agreement with earlier studies that found that partial sleep deprivation from 8 hours to $4-5$ hours of sleep per night increases pre-diabetic symptoms such as glucose intolerance and insulin resistance, as well as other changes in the endocrine function. ${ }^{6,40}$ Additionally, apart from direct effects of sleep restriction on glucose and insulin level, it also has an indirect effect on the risk of diabetes. Sleep deprivation can cause an elevation in 


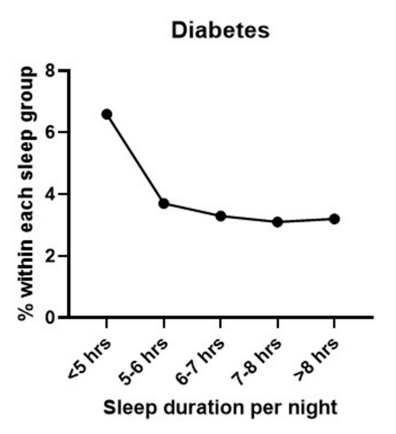

Ischaemic heart diseases

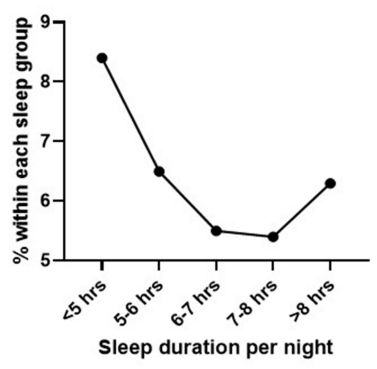

Diseases of arteries, arterioles and capillaries

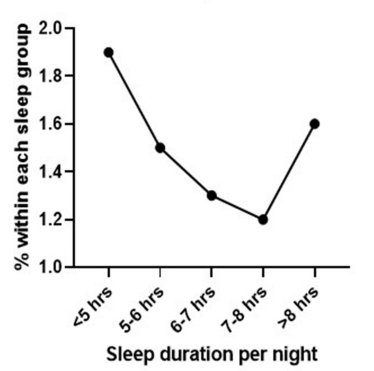

Disorders of glucose regulation and pancreatic internal secretion

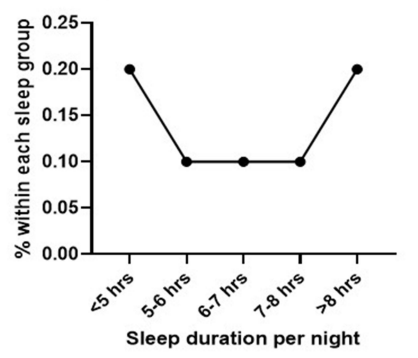

Pulmonary heart diseases

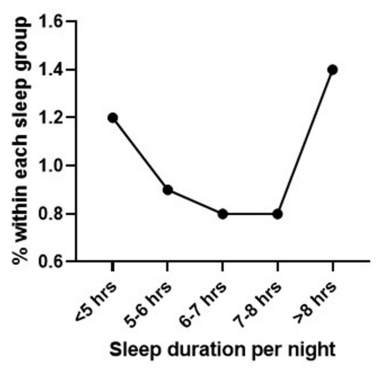

Mood disorder

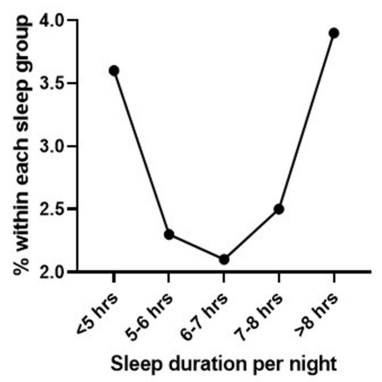

Obesity and other

hyperalimentation

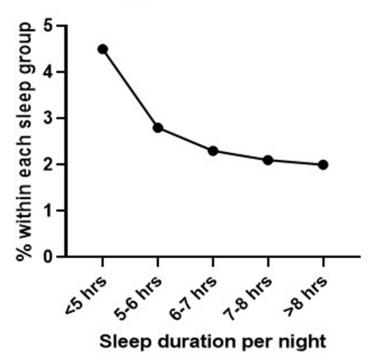

Cerebrovascular diseases

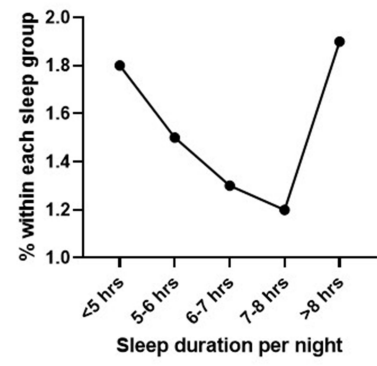

Schizophrenia/schizotypal/ delusional disorders

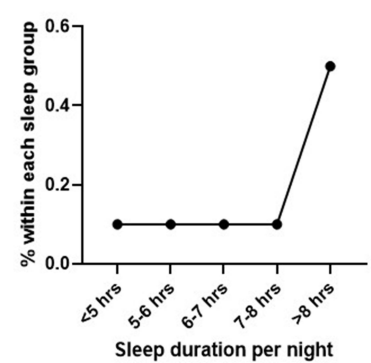

Hypertensive diseases

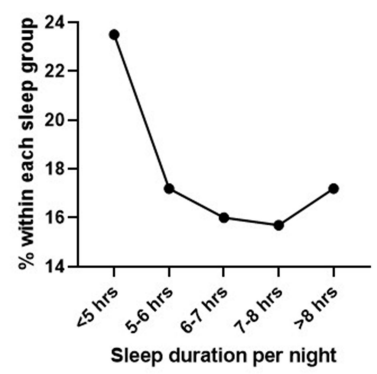

Other forms of heart diseases

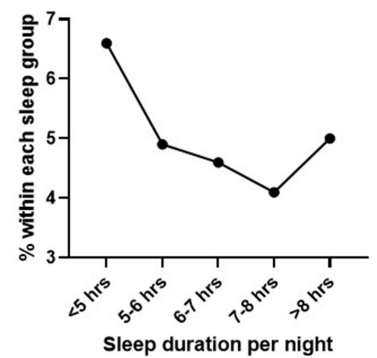

Organic mental disorder

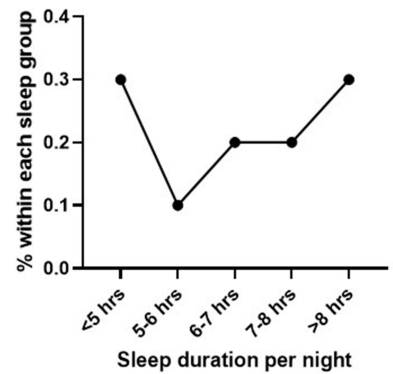

Figure 2 Graphs demonstrating the "U-shaped" relationship between sleep duration and various diseases.

ghrelin level, which promotes hunger and weight gain. ${ }^{41}$ This in turn increases the risk of diabetes and other metabolic syndromes. This suggests that partial sleep deprivation might accelerate the severity of age-related chronic disorders. ${ }^{6,40}$ The risk of organic mental disorders and mood disorders are increased by $106 \%$ and $44 \%$ in short sleepers who sleep $<5$ hours/night compared to those who sleep 7-8 hours, respectively. Mood disorders are common among patients with chronic sleep problems and are strongly associated with sleep complaints; however, the causal relationship is often thought to be bidirectional. ${ }^{42}$ An underlying mechanism is that sleep deprivation can induce neuroinflammation including the activation of leucine-rich repeat protein-3 inflammasome, which then induces depressive-like behaviours, mood disorder and cognitive diseases. ${ }^{43-45}$ The risk of hypertensive diseases increased by $36 \%$ among the extreme short sleepers. This supports the Sleep Heart Health Study, which showed that
$<6$ hours of sleep increased the prevalence of hypertension by $66 \%{ }^{46}$ During sleep, blood pressure reduces by 10 $20 \%$. When this reduction is absent, the risk of resistant hypertension and cardiovascular mortality increases. The odds of incident hypertension increases by $37 \%$ with each hour of reduced sleep duration. ${ }^{47}$ Therefore, it is not surprising that cardiovascular risk is also elevated by sleep deprivation as found in the current study. The risk of various heart diseases is $25-37 \%$ higher in participants who sleep $<5$ hours/night compared to those who sleep 7-8 hours/night. These results support previous studies, which have established that sleeping for 4-6 hours/night compared to 7-8 hours/night leads to greater risk of coronary heart disease and acute myocardial infarction. ${ }^{7,48,49}$ Various studies have shown that the lack of sleep could cause an increase in the activity of sympathetic nervous system and a decreased level of parasympathetic cardiovascular modulation, leading to an increase in blood 
Table 3 Binary Regression Model Showing Odds Ratio of Various Diseases

\begin{tabular}{|c|c|c|c|c|c|c|c|c|c|}
\hline & \multirow{2}{*}{$\begin{array}{c}\begin{array}{c}7-8 \\
\text { Hours }\end{array} \\
\text { OR }\end{array}$} & \multicolumn{2}{|c|}{$<5$ Hours } & \multicolumn{2}{|c|}{ 5-6 Hours } & \multicolumn{2}{|c|}{ 6-7 Hours } & \multicolumn{2}{|c|}{$>8$ Hours } \\
\hline & & $\begin{array}{c}\text { OR } \\
(95 \% \mathrm{Cl})\end{array}$ & P-value & $\begin{array}{c}\text { OR } \\
(95 \% \mathrm{Cl})\end{array}$ & P-value & $\begin{array}{c}\text { OR } \\
(95 \% \mathrm{Cl})\end{array}$ & P-value & $\begin{array}{c}\text { OR } \\
(95 \% \mathrm{Cl})\end{array}$ & P-value \\
\hline Diabetes & 1.00 & $1.58(1.40-1.77)$ & $<0.001$ & $1.05(0.93-1.18)$ & 0.436 & $1.02(0.91-1.15)$ & 0.679 & $1.02(0.83-1.25)$ & 0.883 \\
\hline $\begin{array}{l}\text { Disorders of glucose } \\
\text { regulation and } \\
\text { pancreatic internal } \\
\text { secretion }\end{array}$ & 1.00 & $1.72(0.97-3.07)$ & 0.064 & $1.18(0.66-2.11)$ & 0.575 & $0.82(0.45-1.48)$ & 0.505 & $1.80(0.78-4.14)$ & 0.169 \\
\hline $\begin{array}{l}\text { Obesity and other } \\
\text { hyperalimentation }\end{array}$ & 1.00 & $1.48(1.28-1.70)$ & $<0.001$ & $1.12(0.97-1.29)$ & 0.115 & $1.04(0.90-1.19)$ & 0.613 & $0.92(0.71-1.19)$ & 0.524 \\
\hline $\begin{array}{l}\text { Organic mental } \\
\text { disorder }\end{array}$ & 1.00 & $2.06(1.26-3.37)$ & 0.004 & $0.91(0.53-1.56)$ & 0.733 & $1.32(0.82-2.14)$ & 0.256 & $2.16(1.10-4.25)$ & 0.026 \\
\hline $\begin{array}{l}\text { Schizophrenia/ } \\
\text { schizotypal/delusional } \\
\text { disorders }\end{array}$ & 1.00 & $1.36(0.68-2.72)$ & 0.383 & $0.84(0.42-1.70)$ & 0.627 & $0.95(0.49-1.83)$ & 0.877 & $5.6 \mid(2.8|-||.2|)$ & $<0.001$ \\
\hline Mood disorder & 1.00 & $1.44(1.26-1.65)$ & $<0.001$ & $0.89(0.78-1.02)$ & 0.093 & $0.84(0.74-0.95)$ & 0.007 & $1.55(1.28-1.87)$ & $<0.001$ \\
\hline $\begin{array}{l}\text { Hypertensive } \\
\text { diseases }\end{array}$ & 1.00 & $1.36(1.28-1.44)$ & $<0.001$ & $1.07(1.01-1.13)$ & 0.025 & $1.03(0.97-1.09)$ & 0.312 & $1.11(1.01-1.22)$ & 0.039 \\
\hline $\begin{array}{l}\text { Ischaemic heart } \\
\text { diseases }\end{array}$ & 1.00 & $1.25(1.14-1.37)$ & $<0.001$ & $1.13(1.04-1.24)$ & 0.007 & $1.01(0.93-1.10)$ & 0.819 & $1.17(1.01-1.36)$ & 0.040 \\
\hline $\begin{array}{l}\text { Pulmonary heart } \\
\text { diseases }\end{array}$ & 1.00 & $1.33(1.05-1.68)$ & 0.017 & $1.04(0.83-1.31)$ & 0.712 & $0.97(0.78-1.22)$ & 0.818 & $1.72(1.25-2.38)$ & 0.001 \\
\hline $\begin{array}{l}\text { Other form of heart } \\
\text { disease }\end{array}$ & 1.00 & $1.37(1.24-1.52)$ & $<0.001$ & $1.16(1.05-1.28)$ & 0.004 & $1.11(1.01-1.23)$ & 0.032 & $1.22(1.03-1.44)$ & 0.020 \\
\hline $\begin{array}{l}\text { Cerebrovascular } \\
\text { disease }\end{array}$ & 1.00 & $1.27(1.05-1.54)$ & 0.013 & $1.17(0.98-1.41)$ & 0.086 & $1.05(0.88-1.25)$ & 0.609 & $1.58(1.20-2.07)$ & 0.001 \\
\hline $\begin{array}{l}\text { Diseases of arteries, } \\
\text { arterioles and } \\
\text { capillaries }\end{array}$ & 1.00 & $1.36(1.13-1.65)$ & 0.001 & $1.26(1.05-1.51)$ & 0.014 & $1.14(0.96-1.36)$ & 0.144 & $1.32(0.98-1.76)$ & 0.065 \\
\hline
\end{tabular}

Notes: Binary regression model was adjusted for age, gender and Townsend deprivation index. 7-8 hours sleep group is used as the reference group. Abbreviations: $\mathrm{OR}$, odds ratio; $\mathrm{Cl}$, confidence interval.

pressure. $^{50,51}$ Sleep deprivation is also associated with elevated nocturnal catecholamine and C-reactive protein levels, which in turn contributes to cardiovascular diseases through inflammation in the vascular wall, as well as vasoconstrictive and prothrombotic processes. ${ }^{52,53}$

Another important finding was that when combining short and long sleep durations with sleep fragmentation to compare optimal and less optimal sleep, the current study found that those with less optimal sleep have significantly higher odds for diabetes, obesity, various heart diseases. These results match those observed in earlier studies. Those with a sleep duration shorter or longer than $7-8$ hours/night and highly fragmented sleep is associated with significantly higher odds of high BMI and obesity. This relationship may partly be due to dysregulated glucose metabolism caused by frequent arousals. ${ }^{54,55}$ Inflammatory-related white blood cells including monocytes and neutrophils are also increased by fragmented sleep, which leads to atherosclerosis and contributes to the development of hypertension and various heart diseases. ${ }^{56}$ However, those with poorer health such as metabolic diseases and heart problems may experience shorter and more disturbed sleep. Therefore, the relationship between sleep fragmentation and diseases may be bidirectional. 
Table 4 Binary Regression Model Showing Odds Ratio of Various Diseases

\begin{tabular}{|c|c|c|c|}
\hline Primary Care Data Code & Optimal Sleep (OR) & Less Optimal Sleep (OR, 95\% Cl) & P-value \\
\hline Diabetes & 1.00 & $1.42(1.32-1.53)$ & $<0.001$ \\
\hline Disorders of glucose regulation and pancreatic internal secretion & 1.00 & $1.73(1.21-2.48)$ & 0.003 \\
\hline Obesity and other hyperalimentation & 1.00 & $1.40(1.28-1.52)$ & $<0.001$ \\
\hline Organic mental disorder & 1.00 & $1.77(1.31-2.40)$ & $<0.001$ \\
\hline Schizophrenia/schizotypal/delusional disorders & 1.00 & $2.10(1.4 I-3.14)$ & $<0.001$ \\
\hline Mood disorder & 1.00 & $1.68(1.54-1.83)$ & $<0.001$ \\
\hline Hypertensive diseases & 1.00 & $1.22(1.18-1.27)$ & $<0.001$ \\
\hline Ischaemic heart diseases & 1.00 & $1.12(1.05-1.19)$ & $<0.001$ \\
\hline Pulmonary heart diseases & 1.00 & $1.37(1.18-1.59)$ & $<0.001$ \\
\hline Other form of heart disease & 1.00 & $1.13(1.06-1.21)$ & $<0.001$ \\
\hline Cerebrovascular disease & 1.00 & $1.10(0.98-1.24)$ & 0.114 \\
\hline Diseases of arteries, arterioles and capillaries & 1.00 & $1.10(0.98-1.24)$ & 0.106 \\
\hline
\end{tabular}

Notes: Binary regression model was adjusted for age, gender and Townsend deprivation index. Optimal sleep is used as the reference group. Abbreviations: OR, odds ratio; $\mathrm{Cl}$, confidence interval.

The main strength of the current UK Biobank study is the extensive information collected on a large sample size tracked over time. The accelerometry data allowed the possibility of measuring sleep duration objectively using open access algorithms. This is likely to be more accurate than self-reported sleep duration previously reported in this cohort. Similarly, a comprehensive and complete primary care dataset is likely to provide reliable health-related measurements compared to short questions of self-reported health as previously collected. This is by far the largest UK accelerometry cohort to study sleep duration as a specific risk factor of metabolic and mental health. One of the limitations is that analysis could not be controlled for obstructive sleep apnoea due to small number of cases within the UK Biobank. The lack of specific assessment for conditions such as obstructive sleep apnoea remains underdiagnosed in the general population over the age of 50 and the specific population studied within the UK Biobank. Additionally, those in better health are more likely to attend assessment visits over time.

In conclusion, a significant "U-shaped" association between sleep duration and disease status was found, suggesting that 6-8 hours of sleep each night is associated with better long-term health. Short and long sleep durations increase the odds of metabolic and mental diseases.

\section{Acknowledgments}

The authors would like to thank all the participants of the UK Biobank for volunteering in this research and investigators for making this study possible. Michael Catt, Mark Birch-Machin and Kirstie Anderson are equal senior authors and co-supervisors.

\section{Disclosure}

This work is supported by UK Research and Innovation/ Biotechnology and Biological Sciences Research Council (UKRI/BBSRC, BB/P504397/1, awarded to Mark BirchMachin as principal investigator) in collaboration with Unilever. Dr David A Gunn is an employee of Unilever during the conduct of the study. The authors report no other conflicts of interest in this work.

\section{References}

1. Hirshkowitz M, Whiton K, Albert SM, et al. National Sleep Foundation's sleep time duration recommendations: methodology and results summary. Sleep Health. 2015;1(1):40-43. doi:10.1016/j. sleh.2014.12.010

2. Gallicchio L, Kalesan B. Sleep duration and mortality: a systematic review and meta-analysis. J Sleep Res. 2009;18(2):148-158. doi:10.1111/j.1365-2869.2008.00732.x

3. Ferrie JE, Shipley MJ, Cappuccio FP, et al. A prospective study of change in sleep duration: associations with mortality in the Whitehall II cohort. Sleep. 2007;30(12):1659-1666. doi:10.1093/sleep/30.12.1659

4. Smagula SF, Stone KL, Redline S, et al. Actigraphy- and polysomnography-measured sleep disturbances, inflammation, and mortality among older men. Psychosom Med. 2016;78(6):686-696. doi:10.1097/PSY.0000000000000312

5. Hublin C, Partinen M, Koskenvuo M, Kaprio J. Sleep and mortality: a population-based 22-year follow-up study. Sleep. 2007;30 (10):1245-1253. doi:10.1093/sleep/30.10.1245

6. Ayas NT, White DP, Al-Delaimy WK, et al. A prospective study of self-reported sleep duration and incident diabetes in women. Diabetes Care. 2003;26(2):380-384. doi:10.2337/diacare.26.2.380

7. Ayas NT, White DP, Manson JE, et al. A prospective study of sleep duration and coronary heart disease in women. Arch Intern Med. 2003;163(2):205-209. doi:10.1001/archinte.163.2.205

8. Song Q, Liu X, Zhou W, Wang X, Wu S. Changes in sleep duration and risk of metabolic syndrome: the Kailuan prospective study. Sci Rep. 2016;6(1):36861. doi:10.1038/srep36861

9. Spira AP, Stone KL, Redline S, et al. Actigraphic sleep duration and fragmentation in older women: associations with performance across cognitive domains. Sleep. 2017;40:8. doi:10.1093/sleep/zsx073 
10. Patel SR, Ayas NT, Malhotra MR, et al. A prospective study of sleep duration and mortality risk in women. Sleep. 2004;27(3):440-444. doi:10.1093/sleep/27.3.440

11. Tamakoshi A, Ohno Y. Self-reported sleep duration as a predictor of all-cause mortality: results from the JACC study, Japan. Sleep. 2004;27(1):51-54.

12. Yang L, Xu Z, He M, et al. Sleep Duration and midday napping with 5-year incidence and reversion of metabolic syndrome in middle-aged and older Chinese. Sleep. 2016;39(11):1911-1918. doi:10.5665/sleep. 6214

13. Smagula SF, Harrison S, Cauley JA, et al. Determinants of change in objectively assessed sleep duration among older men. Am J Epidemiol. 2017;185(10):933-940. doi:10.1093/aje/kwx014

14. Mander BA, Winer JR, Walker MP. Sleep and human aging. Neuron. 2017;94(1):19-36. doi:10.1016/j.neuron.2017.02.004

15. Chaput J-P, Dutil C, Sampasa-Kanyinga H. Sleeping hours: what is the ideal number and how does age impact this? Nat Sci Sleep. 2018;10:421-430. doi:10.2147/NSS.S163071

16. Redline S, Kirchner HL, Quan SF, Gottlieb DJ, Kapur V, Newman A. The effects of age, sex, ethnicity, and sleep-disordered breathing on sleep architecture. Arch Intern Med. 2004;164(4):406-418. doi:10.1001/archinte.164.4.406

17. Jehan S, Masters-Isarilov A, Salifu I, et al. Sleep disorders in postmenopausal women. J Sleep Disord Ther. 2015;4(5):1000212.

18. Vaz Fragoso CA, Gill TM. Sleep complaints in community-living older persons: a multifactorial geriatric syndrome. J Am Geriatr Soc. 2007;55(11):1853-1866. doi:10.1111/j.1532-5415.2007.01399.x

19. Fatima Y, Bucks RS, Mamun AA, et al. Sleep trajectories and mediators of poor sleep: findings from the longitudinal analysis of 41,094 participants of the UK Biobank cohort. Sleep Med. 2020;76:120-127. doi:10.1016/j.sleep.2020.10.020

20. Patterson F, Malone SK, Grandner MA, Lozano A, Perkett M, Hanlon A. Interactive effects of sleep duration and morning/evening preference on cardiovascular risk factors. Eur J Public Health. 2018;28(1):155-161. doi:10.1093/eurpub/ckx029

21. Henry A, Katsoulis M, Masi S, et al. The relationship between sleep duration, cognition and dementia: a Mendelian randomization study. Int J Epidemiol. 2019;48(3):849-860. doi:10.1093/ije/dyz071

22. Kyle SD, Sexton C, Feige B, Rutter M, Spiegelhalder K. 0323 Sleep and cognitive performance: cross-sectional associations from the UK Biobank (N=477,966). Sleep. 2017;40(suppl_1):A119-A20. doi:10.1093/sleepj/zsx050.322

23. Ancoli-Israel S, Cole R, Alessi C, Chambers M, Moorcroft W, Pollak CP. The role of actigraphy in the study of sleep and circadian rhythms. Sleep. 2003;26(3):342-392. doi:10.1093/sleep/26.3.342

24. Biobank U. UK Biobank: protocol for a large-scale prospective epidemiological resource2007. Available from: https://www.ukbio bank.ac.uk/media/gnkeyh2q/study-rationale.pdf. Accessed October $6,2021$.

25. Doherty A, Jackson D, Hammerla N, et al. Large scale population assessment of physical activity using wrist worn accelerometers: the UK Biobank study. PLoS One. 2017;12(2):e0169649. doi:10.1371/ journal.pone.0169649

26. Biobank U. Primary Care Linked Data Version 1.0September 2019. Available from: file://G:/UK\%20Biobank\%20analysis/Primary\% 20care\%20data/primary_care_data\%20ukbb\%20background.pdf. Accessed October 15, 2021.

27. Jairo HM, Alex VR, Florian H, Séverine S, Vincent T. GGIR: a research community-driven open source R Package for generating physical activity and sleep outcomes from multi-day raw accelerometer data. J Measurement Phys Behav. 2019;2(3):188-196. doi:10.1123/jmpb.2018-0063

28. van Hees VT, Sabia S, Anderson KN, et al. A novel, open access method to assess sleep duration using a wrist-worn accelerometer. PLoS One. 2015;10(11):e0142533. doi:10.1371/ journal.pone. 0142533
29. van Hees VT, Sabia S, Jones SE, et al. Estimating sleep parameters using an accelerometer without sleep diary. Sci Rep. 2018;8 (1):12975. doi:10.1038/s41598-018-31266-Z

30. Sundararajan K, Georgievska S, Te Lindert BHW, et al. Sleep classification from wrist-worn accelerometer data using random forests. Sci Rep. 2021;11(1):24. doi:10.1038/s41598-020-79217-x

31. Li X, Lin L, Lv L, et al. U-shaped relationships between sleep duration and metabolic syndrome and metabolic syndrome components in males: a prospective cohort study. Sleep Med. 2015;16 (8):949-954. doi:10.1016/j.sleep.2015.03.024

32. Li Y, Wu Y, Zhai L, Wang T, Sun Y, Zhang D. Longitudinal association of sleep duration with depressive symptoms among middle-aged and older Chinese. Sci Rep. 2017;7(1):11794. doi:10.1038/s41598017-12182-0

33. Cassidy S, Chau JY, Catt M. Cross-sectional study of diet, physical activity, television viewing and sleep duration in 233110 adults from the UK Biobank; the behavioural phenotype of cardiovascular disease and type 2 diabetes. BMJ Open. 2016;6.

34. Zeitzer JM, Blackwell T, Hoffman AR, Cummings S, Ancoli-Israel S, Stone K. Daily patterns of accelerometer activity predict changes in sleep, cognition, and mortality in older men. J Gerontol a Biol Sci Med Sci. 2018;73(5):682-687. doi:10.1093/gerona/glw250

35. Fung Maple M, Peters K, Ancoli-Israel S, Redline S, Stone Katie L, Barrett-Connor E. Total sleep time and other sleep characteristics measured by actigraphy do not predict incident hypertension in a cohort of community-dwelling older men. J Clin Sleep Med. 2017;1:585-591.

36. Davis KAS, Coleman JRI, Adams M, et al. Mental health in UK Biobank - development, implementation and results from an online questionnaire completed by 157366 participants: a reanalysis. BJPsych Open. 2020;6(2):e18. doi:10.1192/bjo.2019.100

37. Lauderdale DS, Chen J-H, Kurina LM, Waite LJ, Thisted RA. Sleep duration and health among older adults: associations vary by how sleep is measured. J Epidemiol Community Health. 2016;70 (4):361-366. doi:10.1136/jech-2015-206109

38. Yin J, Jin X, Shan Z, et al. Relationship of sleep duration with allcause mortality and cardiovascular events: a systematic review and dose-response meta-analysis of prospective cohort studies. J Am Heart Assoc. 2018. 6;9:e005947.

39. Knutson KL, Turek FW. The U-shaped association between sleep and health: the 2 peaks do not mean the same thing. Sleep. 2006;29 (7):878-879. doi:10.1093/sleep/29.7.878

40. Spiegel K, Leproult R, Van Cauter E. Impact of sleep debt on metabolic and endocrine function. Lancet. 1999;354 (9188):1435-1439. doi:10.1016/S0140-6736(99)01376-8

41. Schmid SM, Hallschmid M, Jauch-Chara K, Born J, Schultes B. A single night of sleep deprivation increases ghrelin levels and feelings of hunger in normal-weight healthy men. J Sleep Res. 2008;17(3):331-334. doi:10.1111/j.1365-2869.2008.00662.x

42. Benca RM, Okawa M, Uchiyama M, et al. Sleep and mood disorders. Sleep Med Rev. 1997;1(1):45-56. doi:10.1016/S1087-0792(97) 90005-8

43. Verkhratsky A, Nedergaard M, Steardo L, Editorial: LB. Sleep and mood disorders. Front Psychiatry. 2020;10:981. doi:10.3389/ fpsyt.2019.00981

44. Xia M, Li X, Yang L, et al. The ameliorative effect of fluoxetine on neuroinflammation induced by sleep deprivation. $J$ Neurochem. 2018;146(1):63-75. doi:10.1111/jnc.14272

45. Alcocer-Gómez E, Cordero MD. NLRP3 inflammasome: a new target in major depressive disorder. CNS Neurosci Ther. 2014;20 (3):294-295. doi:10.1111/cns.12230

46. Gottlieb DJ, Redline S, Nieto FJ, et al. Association of usual sleep duration with hypertension: the Sleep Heart Health Study. Sleep. 2006;29(8):1009-1014. doi:10.1093/sleep/29.8.1009

47. Calhoun DA, Harding SM. Sleep and hypertension. Chest. 2010;138 (2):434-443. doi:10.1378/chest.09-2954 
48. Kripke DF, Simons RN, Garfinkel L, Hammond EC. Short and long sleep and sleeping pills. Is increased mortality associated? Arch Gen Psychiatry. 1979;36(1):103-116. doi:10.1001/ archpsyc.1979.01780010109014

49. Liu Y, Tanaka H. Overtime work, insufficient sleep, and risk of non-fatal acute myocardial infarction in Japanese men. Occup Environ Med. 2002;59(7):447-451. doi:10.1136/oem.59.7.447

50. Zhong X, Hilton HJ, Gates GJ, et al. Increased sympathetic and decreased parasympathetic cardiovascular modulation in normal humans with acute sleep deprivation. J Appl Physiol. 2005;98 (6):2024-2032. doi:10.1152/japplphysiol.00620.2004

51. Tochikubo O, Ikeda A, Miyajima E, Ishii M. Effects of insufficient sleep on blood pressure monitored by a new multibiomedical recorder. Hypertension. 1996;27(6):1318-1324. doi:10.1161/01. HYP.27.6.1318

52. Irwin M, Thompson J, Miller C, Gillin JC, Ziegler M. Effects of sleep and sleep deprivation on catecholamine and interleukin-2 levels in humans: clinical implications. J Clin Endocrinol Metab. 1999;84 (6):1979-1985.
53. Meier-Ewert HK, Ridker PM, Rifai N, et al. Effect of sleep loss on C-reactive protein, an inflammatory marker of cardiovascular risk. J Am Coll Cardiol. 2004;43(4):678-683. doi:10.1016/j. jacc.2003.07.050

54. van den Berg JF, Knvistingh Neven A, Tulen JHM, et al. Actigraphic sleep duration and fragmentation are related to obesity in the elderly: the Rotterdam Study. Int $J$ Obes. 2008;32(7):1083-1090. doi:10.1038/ijo.2008.57

55. Zhao B, Sun S, He X, Yang J, Ma X, Yan B. Sleep fragmentation and the risk of obesity: the Sleep Heart Health Study. Obesity. 2021;29 (8):1387-1393. doi:10.1002/oby.23193

56. Vallat R, Shah VD, Redline S, Attia P, Walker MP. Broken sleep predicts hardened blood vessels. PLoS Biol. 2020;18(6):e3000726. doi:10.1371/journal.pbio.3000726

\section{Publish your work in this journal}

Nature and Science of Sleep is an international, peer-reviewed, open access journal covering all aspects of sleep science and sleep medicine, including the neurophysiology and functions of sleep, the genetics of sleep, sleep and society, biological rhythms, dreaming, sleep disorders and therapy, and strategies to optimize healthy sleep.
The manuscript management system is completely online and includes a very quick and fair peer-review system, which is all easy to use. Visit http://www.dovepress.com/testimonials.php to read real quotes from published authors. 